University of South Carolina

Scholar Commons

6-7-2011

\title{
A Generic Bamboo-Based Carbothermal Method for Preparing Carbide (SiC, B4C, TiC, TaC, NbC, $\mathrm{Ti}_{x} \mathrm{Nb}_{1-\mathrm{x}} \mathrm{C}$, and $\mathrm{Ta}_{\mathrm{x}} \mathrm{Nb}_{1-\mathrm{x}} \mathrm{C}$ ) Nanowires
}

Xinyong Tao

Yiping Li

Jun Du

Yang Xia

Yingchao Yang

See next page for additional authors

Follow this and additional works at: https://scholarcommons.sc.edu/emec_facpub

Part of the Applied Mechanics Commons, and the Energy Systems Commons

Publication Info

Published in Journal of Materials Chemistry, Volume 21, Issue 25, 2011, pages 9095-9102.

(C) Journal of Materials Chemistry 2011, Royal Society of Chemistry.

This article cannot be redistributed or further made available.

This article was first published by the Royal Society of Chemistry and can be found at http://dx.doi.org/ 10.1039/C1JM10730E

Tao, X., Li, Y., Du, J., Xia, Y., Yang, Y., Huang, H., Gan, Y., Zhang, W., \& Li, X. (7 June 2011). A Generic Bamboo-Based Carbothermal Method for Preparing Carbide (SiC, $\mathrm{B}_{4} \mathrm{C}, \mathrm{TiC}, \mathrm{TaC}, \mathrm{NbC}, \mathrm{Ti}_{\mathrm{x}} \mathrm{Nb}_{1-\mathrm{x}} \mathrm{C}$, and $\mathrm{Ta}_{\mathrm{x}}$ $\mathrm{Nb}_{1-\mathrm{x}} \mathrm{C}$ ) Nanowires. Journal of Materials Chemistry, 21 (25), 9095 - 9102. http://dx.doi.org/10.1039/ C1JM10730E

This Article is brought to you by the Mechanical Engineering, Department of at Scholar Commons. It has been accepted for inclusion in Faculty Publications by an authorized administrator of Scholar Commons. For more information, please contact digres@mailbox.sc.edu. 


\section{Author(s)}

Xinyong Tao, Yiping Li, Jun Du, Yang Xia, Yingchao Yang, Hui Huang, Yongping Gan, Wenkui Zhang, and Xiaodong $\mathrm{Li}$ 


\title{
Journal of

\section{A generic bamboo-based carbothermal method for preparing carbide (SiC, $\mathrm{B}_{4} \mathrm{C}, \mathrm{TiC}, \mathrm{TaC}, \mathrm{NbC}, \mathrm{Ti}_{x} \mathrm{Nb}_{1-x} \mathrm{C}$, and $\mathrm{Ta}_{x} \mathrm{Nb}_{1-x} \mathrm{C}$ ) nanowires}

\author{
Xinyong Tao, ${ }^{a}$ Yiping Li, ${ }^{a}$ Jun Du, ${ }^{a}$ Yang Xia,${ }^{a}$ Yingchao Yang, ${ }^{b}$ Hui Huang, ${ }^{a}$ Yongping Gan, ${ }^{a}$ Wenkui Zhang ${ }^{* a}$ \\ and Xiaodong $\mathrm{Li}^{* b}$
}

Received 18th February 2011, Accepted 11th April 2011

DOI: 10.1039/c1jm10730e

Finding a general procedure to produce a whole class of materials in a similar way is a desired goal of materials chemistry. In this work, we report a new bamboo-based carbothermal method to prepare nanowires of covalent carbides $\left(\mathrm{SiC}\right.$ and $\left.\mathrm{B}_{4} \mathrm{C}\right)$ and interstitial carbides $\left(\mathrm{TiC}, \mathrm{TaC}, \mathrm{NbC}, \mathrm{Ti}_{x} \mathrm{Nb}_{1-x} \mathrm{C}\right.$, and $\mathrm{Ta}_{x} \mathrm{Nb}_{1-x} \mathrm{C}$ ). The use of natural nanoporous bamboo as both the renewable carbon source and the template for the formation of catalyst particles greatly simplifies the synthesis process. Based on the structural, morphological and elemental analysis, volatile oxides or halides assisted vapour-liquidsolid growth mechanism was proposed. This bamboo based carbothermal method can be generalized to other carbide systems, providing a general, one-pot, convenient, low-cost, nontoxic, mass production, and innovative strategy for the synthesis of carbide nanostructures.

\section{Introduction}

Carbides can be generally classified into the following three types: covalent, interstitial and saline carbides. Covalent carbides including $\mathrm{SiC}$ and $\mathrm{B}_{4} \mathrm{C}$ are formed by strong and directional bonding, where the carbon atoms are bonded to the $\mathrm{Si}$ or $\mathrm{B}$ atoms by sharing a pair of electrons. Interstitial carbides such as $\mathrm{TiC}, \mathrm{TaC}$, and $\mathrm{NbC}$ are produced by incorporating carbon atoms into the interstitial sites of their parent metals, which combine the physical properties of three different classes of materials: covalent solids, ionic crystals, and transition metals. ${ }^{1,2}$ Covalent and interstitial carbides, in general, have high melting points, excellent resistance to oxidation and corrosion, low thermal-expansion coefficient, ultra-high hardness, and high elastic modulus. ${ }^{2-8}$ The combination of these superior properties gives rise to numerous applications, especially under extreme conditions, for example, light weight armors, abrasive wearresistant materials, high temperature resistant composites, high speed cutting tools, and high temperature microelectronics. ${ }^{2-9}$ Over the last 10 years, one-dimensional (1D) carbide nanostructures such as nanowires (NWs) have attracted tremendous attention because of their size-dependent optical, electronic, mechanical, and sensing properties, opening up unprecedented opportunities to construct nanodevices with new functionalities which could be achieved at the micro/macroscales. ${ }^{10-34}$

To date, various techniques including carbon nanotube (CNT) confined reaction, ${ }^{21,27,33}$ chemical vapor deposition, ${ }^{22,30,35}$ carbon

${ }^{a}$ College of Chemical Engineering and Materials Science, Zhejiang University of Technology, Hangzhou, 310014, China.E-mail: msechem@, zjut.edu.cn

${ }^{b}$ Department of Mechanical Engineering, University of South Carolina, 300 Main Street, Columbia, SC,29208, USA. E-mail: lixiao@cec.sc.edu thermal reduction, ${ }^{20,32}$ and pyrolysis of polymeric precursors ${ }^{18,36}$ have been developed for the preparation of 1D carbide nanostructures. To synthesize these carbide nanostructures, carbon source is essential. The pie chart (Fig. 1a) shows the proportion of different categories of carbon sources used in the current synthetic methods. This analysis is based on the Web of Science database. Engineering materials such as CNTs (16.79\%), graphite (GR) $(14.50 \%)$, polymers (PS) $(25.95 \%)$, hydrocarbon gases (HG) $(20.61 \%)$, activated carbon (AC) $(16.03 \%)$, and carbon black (CB) $(5.34 \%)$ were usually selected as carbon source (Fig. 1a). Only a few biomaterials (BM) $(0.76 \%)$ such as cotton have been selected as the carbon source for the growth of $\mathrm{B}_{4} \mathrm{C}$ nanowires in our recent work. ${ }^{17}$ These artificial/engineered carbon sources including CNTs, GR, PS, HG, AC, and CB, are usually derived from fossil fuels such as petroleum, coal, and natural gas, which are non-renewable. To a large extent, they are not economical and conducive for sustainable development. The unbalanced distribution of fossil fuels and considerable price fluctuation are forcing the chemical industry to find alternative

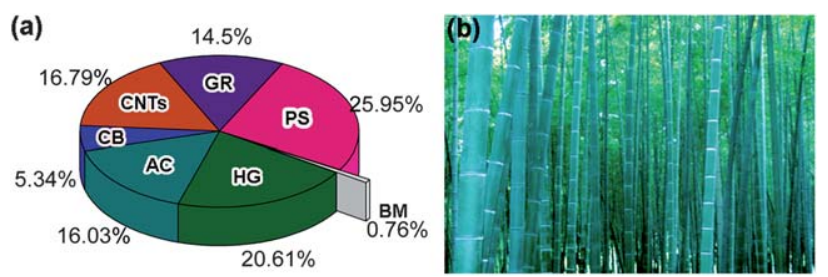

Fig. 1 (a) A pie chart showing the proportion of different categories of carbon sources used in the current synthetic methods for 1D carbide nanostructures. (b) Digital camera image of bamboo. 
raw materials such as renewable plants for the production of basic chemicals.

Bamboo is a large, woody-grasses member of the family of Bambusoideae encompassing about 1250 species within 75 genera worldwide. ${ }^{37}$ Found in tropical and subtropical areas over many continents except Europe, the major producing region is Asia with a total annual production of 6 to 7 million tonnes. Bamboo takes as short as 2 years to grow up in controlled forests. It is recognized as the world's fastest growing plant, which has environmental advantages over long-cycle renewable resources. Although bamboo has been used for handicrafts and building materials in Asia for thousands of years, its potential contribution to sustainable natural resource management has only recently been recognized. In this work, we demonstrate a new bamboo-based carbothermal method to prepare carbide NWs using bamboo as both the sustainable carbon source and the natural porous template. A series of carbide $\left(\mathrm{SiC}, \mathrm{B}_{4} \mathrm{C}, \mathrm{TiC}\right.$, $\mathrm{TaC}, \mathrm{NbC}, \mathrm{Ti}_{x} \mathrm{Nb}_{1-x} \mathrm{C}$, and $\mathrm{Ta}_{x} \mathrm{Nb}_{1-x} \mathrm{C}$ ) NWs can be synthesized via this one-pot, convenient, low-cost, nontoxic, and mass production carbothermal method.

\section{Experimental}

Dried bamboo stems were cut into small pieces, then ball-milled and sieved to obtain bamboo powder. The starting materials used in the preparation of carbide NWs are listed in Table 1. Bamboo powders (2-30 $\mu \mathrm{m}$ ), amorphous $\mathrm{SiO}_{2}$ (A.R., 20-80 nm, Zhoushan Mingri Nanomaterials Co., Ltd.), amorphous B ( $>95$, 20-100 nm, Dandong Chemical Engineering Institute Co., Ltd.), $\mathrm{TiO}_{2}$ (P25, Degussa, Germany), $\mathrm{Ta}_{2} \mathrm{O}_{5}$ (A.R., 0.1-2 $\mu \mathrm{m}$, Aladdin Reagent Co., Ltd.), $\mathrm{Nb}_{2} \mathrm{O}_{5}$ (A.R., 0.1-3 $\mu \mathrm{m}$, Aladdin Reagent Co., Ltd.), $\mathrm{B}_{2} \mathrm{O}_{3}$ (A.R., Sinopharm Chemical Reagent Co., Ltd.), $\mathrm{NaF}$ (A.R., Aladdin Reagent Co., Ltd.), $\mathrm{Fe}\left(\mathrm{NO}_{3}\right)_{3} \cdot 9 \mathrm{H}_{2} \mathrm{O}$ (A.R., Shanghai No.4 Reagent \& H.V. Chemical Co., Ltd.), and Ni $\left(\mathrm{NO}_{3}\right)_{2} \cdot 6 \mathrm{H}_{2} \mathrm{O}$ (A.R., Shantou Guanghua Chemical Factory Co., Ltd.) were used as the raw materials. To start with, the bamboo powder and the precursors were dispersed into the minimum amount of ethanol to form an emulsion under vigorous stirring. After stirring for $2 \mathrm{~h}$, the mixture was dried at $100{ }^{\circ} \mathrm{C}$ for $2 \mathrm{~h}$ and finally ball-milled for $3 \mathrm{~h}$. The ball-milled mixture was placed into a sealed graphite boat put in a horizontal alumina tube furnace (id: $60 \mathrm{~mm}$, length: $1500 \mathrm{~mm}$ ). After calcinating at $1000-1350{ }^{\circ} \mathrm{C}$ for $1-3 \mathrm{~h}$ under argon protection, the furnace was turned off and allowed to cool naturally to room temperature. This bamboo-based carbothermal method is readily expandable for large-scale production (over $120 \mathrm{~g} \mathrm{day}^{-1}$ in our horizontal alumina tube furnace).

The microstructure and the morphology were characterized using a scanning electron microscope (SEM, Hitachi S-4800), a transmission electron microscope (TEM, FEI Tecnai G2 F30) and a high resolution TEM (HRTEM) equipped with an energy dispersive X-ray spectroscopy (EDS) detector.

\section{Results and discussion}

Fig. 2a shows a colored cross-sectional SEM image of a bamboo stem. Vascular bundles (yellow) can be seen containing xylem (larger openings) and phloem (smaller openings). The vessels in xylem could transport water and mineral nutrients from the roots throughout the plant while the porous phloem transports carbohydrates and plant hormones around the plant. The green area in Fig. 2a is woody porous supportive tissue consisting of parenchyma cells with the length over $20 \mu \mathrm{m}$. An enlarged crosssectional SEM image (Fig. 2b) shows that these parenchyma cells are either pentagonal or hexagonal and arranged in a honeycomb pattern. Some triangular interval pores can also be found between three neighbor parenchyma cells (Fig. 2b). Fig. 2c shows the SEM image of the longitudinal section of the bamboo. It can be found that some fiber strands are distributed longitudinally between parenchyma cells. The enlarged SEM image (Fig. 2d) shows that the longitudinal-section of these parenchyma cells is rectangular rather than pentagonal and hexagonal. As indicated

Table 1 Synthesis parameters and the corresponding products

\begin{tabular}{|c|c|c|c|c|c|}
\hline Exp. no. & Bamboo/g & Raw materials/g & Catalyst precursor ${ }^{a} / g$ & Additives/g & Products \\
\hline 1 & 1.14 & $1.02\left(\mathrm{SiO}_{2}\right)$ & $0.36(\mathrm{Fe})$ & No & $\mathrm{SiC} \mathrm{NWs}_{\mathrm{s}}$ \\
\hline 2 & 1.14 & $1.02\left(\mathrm{SiO}_{2}\right)$ & No & No & No SiC NWs \\
\hline 3 & 1.38 & $1.02(\mathrm{~B})$ & $0.51(\mathrm{Ni})$ & $0.06\left(\mathrm{SiO}_{2}\right)$ & $\mathrm{B}_{4} \mathrm{C} \mathrm{NWs}$ \\
\hline 4 & 1.38 & $1.02(\mathrm{~B})$ & $0.51(\mathrm{Ni})$ & No & Few $\mathrm{B}_{4} \mathrm{C}$ NWs \\
\hline 5 & 1.38 & $1.02(\mathrm{~B})$ & No & $0.06\left(\mathrm{SiO}_{2}\right)$ & No $\mathrm{B}_{4} \mathrm{C}$ NWs \\
\hline 6 & 6.51 & $0.59\left(\mathrm{TiO}_{2}\right)$ & $0.23(\mathrm{Ni})$ & $1.40(\mathrm{NaF})$ & TiC NWs \\
\hline 7 & 6.51 & $0.59\left(\mathrm{TiO}_{2}\right)$ & $0.23(\mathrm{Ni})$ & No & No TiC NWs \\
\hline 8 & 6.51 & $0.59\left(\mathrm{TiO}_{2}\right)$ & No & $1.40(\mathrm{NaF})$ & No TiC NWs \\
\hline 9 & 6.59 & $0.61\left(\mathrm{Ta}_{2} \mathrm{O}_{5}\right)$ & $0.24(\mathrm{Ni}), 0.11(\mathrm{Fe})$ & $0.43(\mathrm{NaF})$ & TaC NWs \\
\hline 10 & 6.59 & $0.61\left(\mathrm{Ta}_{2} \mathrm{O}_{5}\right)$ & $0.24(\mathrm{Ni}), 0.11(\mathrm{Fe})$ & No & No TaC NWs \\
\hline 11 & 6.59 & $0.61\left(\mathrm{Ta}_{2} \mathrm{O}_{5}\right)$ & No & $0.43(\mathrm{NaF})$ & No TaC NWs \\
\hline 12 & 5.35 & $2.37\left(\mathrm{Nb}_{2} \mathrm{O}_{5}\right)$ & $0.26(\mathrm{Ni}), 0.31(\mathrm{Fe})$ & $0.38(\mathrm{NaF})$ & $\mathrm{NbC} \mathrm{NWs}$ \\
\hline 13 & 5.35 & $2.37\left(\mathrm{Nb}_{2} \mathrm{O}_{5}\right)$ & $0.26(\mathrm{Ni}), 0.31(\mathrm{Fe})$ & No & No NbC NWs \\
\hline 14 & 5.35 & $2.37\left(\mathrm{Nb}_{2} \mathrm{O}_{5}\right)$ & No & $0.38(\mathrm{NaF})$ & $\mathrm{No} \mathrm{NbC} \mathrm{NWs}$ \\
\hline 15 & 4.66 & $0.31\left(\mathrm{TiO}_{2}\right), 1.03\left(\mathrm{Nb}_{2} \mathrm{O}_{5}\right)$ & $0.23(\mathrm{Fe})$ & $0.33(\mathrm{NaF})$ & $\mathrm{Ti}_{x} \mathrm{Nb}_{1-x} \mathrm{C}$ NWs \\
\hline 16 & 4.66 & $0.31\left(\mathrm{TiO}_{2}\right), 1.03\left(\mathrm{Nb}_{2} \mathrm{O}_{5}\right)$ & $0.23(\mathrm{Fe})$ & No & No $\mathrm{Ti}_{x} \mathrm{Nb}_{1-x} \mathrm{C}$, NWs \\
\hline 17 & 4.66 & $0.31\left(\mathrm{TiO}_{2}\right), 1.03\left(\mathrm{Nb}_{2} \mathrm{O}_{5}\right)$ & No & $0.33(\mathrm{NaF})$ & No $\mathrm{Ti}_{x} \mathrm{Nb}_{1-x} \mathrm{C}$, NWs \\
\hline 18 & 4.91 & $1.81\left(\mathrm{Ta}_{2} \mathrm{O}_{5}\right), 1.09\left(\mathrm{Nb}_{2} \mathrm{O}_{5}\right)$ & $0.24(\mathrm{Ni}), 0.17(\mathrm{Fe})$ & $0.34(\mathrm{NaF})$ & $\mathrm{Ta}_{x} \mathrm{Nb}_{1-x} \mathrm{C}$ NWs \\
\hline 19 & 4.91 & $1.81\left(\mathrm{Ta}_{2} \mathrm{O}_{5}\right), 1.09\left(\mathrm{Nb}_{2} \mathrm{O}_{5}\right)$ & $0.24(\mathrm{Ni}), 0.17(\mathrm{Fe})$ & No & No $\mathrm{Ta}_{x} \mathrm{Nb}_{1-x} \mathrm{C}$ NWs \\
\hline 20 & 4.91 & $1.81\left(\mathrm{Ta}_{2} \mathrm{O}_{5}\right), 1.09\left(\mathrm{Nb}_{2} \mathrm{O}_{5}\right)$ & No & $0.34(\mathrm{NaF})$ & No $\mathrm{Ta}_{x} \mathrm{Nb}_{1-x} \mathrm{C}$ NWs \\
\hline
\end{tabular}



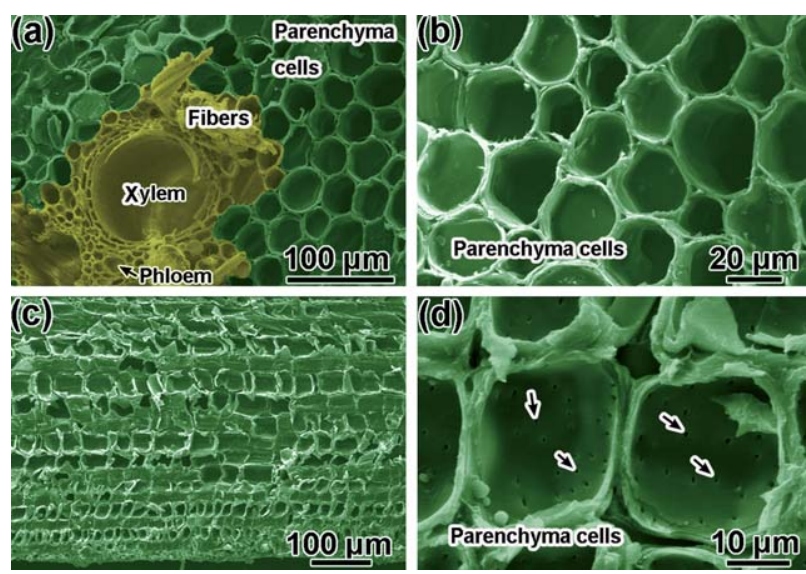

Fig. 2 (a) Typical cross-sectional SEM image of bamboo culm, showing the xylem and phloem. (b) An enlarged cross-sectional SEM image of parenchyma cells. (c) Typical longitudinal SEM image of the bamboo culm. (d) An enlarged longitudinal SEM image, showing the pores in the lateral walls of the parenchyma cells.

by the arrows in Fig. 2d, there are abundant pores in the lateral wall of the parenchyma cell. The bamboo cell walls mainly consist of cellulose, which is constructed from polysaccharide chains arranged into amorphous and crystalline regions. Abundant nanopores with the diameter ranging from 100 to $1000 \mathrm{~nm}$ distribute around the crystalline regions. ${ }^{38}$ The unique hierarchical porous structure of bamboo makes it a perfect natural carbon source, which can absorb the precursors and act as the template for the formation of the catalyst nanoparticles.

We now demonstrate the synthesis of two families of carbides, covalent carbides $\left(\mathrm{SiC}, \mathrm{B}_{4} \mathrm{C}\right)$ and interstitial carbides $(\mathrm{TiC}, \mathrm{TaC}$, $\mathrm{NbC}, \mathrm{Ti}_{x} \mathrm{Nb}_{1-x} \mathrm{C}$, and $\mathrm{Ta}_{x} \mathrm{Nb}_{1-x} \mathrm{C}$ ) to illustrate the universality of this high efficient carbon source-bamboo. The mechanism underlying the synthesis of these carbide nanowires is proposed to involve the reaction of volatile oxide or halide reactants via the classical vapor-liquid-solid (VLS) growth mechanism. A total of seven examples are selected here to illustrate this generalized carbon source.
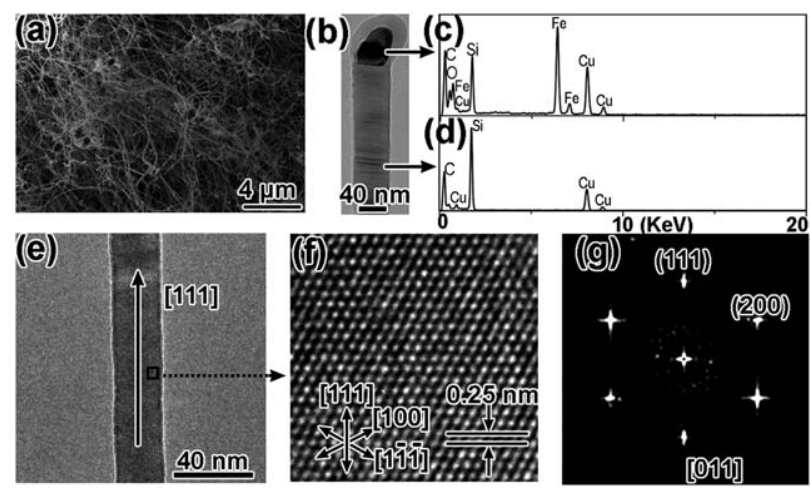

Fig. 3 (a) Typical morphology of the SiC NWs from SEM observation. (b) TEM image of a SiC NW with a catalyst on the tip. (c and d) The corresponding EDS spectra obtained from the catalyst and the NW in (b), respectively. (e) TEM image of a SiC NW. (f) The [011] zone axis HRTEM image of the NW in (e). (g) The corresponding FFT diffraction pattern obtained from $(\mathrm{g})$.
The first example is $\mathrm{SiC}$, an important semiconductor with a wide band gap of $2.30 \mathrm{eV}$ at $300 \mathrm{~K}$. After one-step calcination of the mixture with bamboo powders and the precursors, $\mathrm{SiC}$ NWs (Fig. 3a) with the length over $10 \mu \mathrm{m}$ were obtained. Most of the NWs have catalyst particles on the tip (Fig. 3b), indicating the VLS growth mechanism. The EDS spectrum (Fig. 3d) only from the wire stem shows that the wire contains $\mathrm{C}$ and $\mathrm{Si}$ only with a small amount of $\mathrm{O}$, while the EDS spectrum (Fig. 3c) from the catalyst nanoparticle reveals that the nanoparticle contains $\mathrm{C}, \mathrm{Si}, \mathrm{Fe}$ and $\mathrm{O}(\mathrm{Cu}$ is from the TEM grid). In our experiments, we also found that Fe played a key role in the growth of a $\mathrm{SiC}$ NW. No SiC NWs can be obtained if no Fe was introduced. TEM images (Fig. 3b and e) show that the SiC NW has a clear surface. Fig. $3 \mathrm{f}$ is a HRTEM image taken from the rectangular area marked in Fig. 3e. Fig. 3g shows the corresponding indexed fast Fourier transform (FFT) pattern of the SiC NW in Fig. 3e and $\mathrm{f}$. The space between two adjacent lattice fringes is $0.25 \mathrm{~nm}$, corresponding well to the $\{111\}$ planes of $\beta$-SiC. The clear diffraction spots indicate that the $\mathrm{SiC} \mathrm{NW}$ is a single crystal with the growth direction along [111]. The surface energy of the $\{111\}$ planes in $\beta-\mathrm{SiC}$ is much lower than those of others.

Based on the above experimental results, the growth process of $\beta$-SiC NW can be explained by an oxygen assisted VLS growth mechanism. During the VLS growth of $\mathrm{SiC}$ NW, there must be gas phase transport of carbon and $\mathrm{Si}$ to the $\mathrm{C}-\mathrm{Si}-\mathrm{Fe}-\mathrm{O}$ catalyst. The pyrolysis of bamboo cellulose is able to generate gaseous products (such as $\mathrm{CO}$ and $\mathrm{CH}_{4}$ ) and the compounds in bio-oil (such as hexane, acetaldehyde, acetone, hydroxyacetaldehyde, hydroxyacetone, levoglucosan, etc.), ${ }^{39}$ which can serve as the carbon source. Under high temperature calcination, the carbothermal reduction of silica takes place:

$$
\mathrm{SiO}_{2}(\mathrm{~s})+(2-x) \mathrm{C}(\mathrm{v} \text { or } \mathrm{l}) \rightarrow \mathrm{SiO}_{x}(\mathrm{v})+(2-x) \mathrm{CO}(\mathrm{v})
$$

where s, 1 , and $\mathrm{v}$ refer to the solid state, the liquid state, and the vapor state, respectively. At the initial stage of reaction, it was found that $\mathrm{Fe}$ nanoparticles were formed on the surface of bamboo powders during the calcination of the bamboo with absorbed catalyst precursors. So it is believed that the bamboo acted as a template for the formation of the catalyst particles. The vapor mixture of $\mathrm{SiO}_{x}$ and $\mathrm{C}$ species is transported to the $\mathrm{Fe}$ nanoparticles to form $\mathrm{C}-\mathrm{Si}-\mathrm{Fe}$ nanoparticle:

$$
\mathrm{SiO}_{x}(\mathrm{v})+\mathrm{C}(\mathrm{v} \text { or } 1)+\mathrm{Fe}(1 \text { or s }) \rightarrow \mathrm{Si}-\mathrm{C}-\mathrm{Fe}-\mathrm{O}(1 \text { or s })
$$

When the catalyst nanoparticle supersaturates with $\mathrm{Si}$ and $\mathrm{C}$, the $\mathrm{SiC}$ NW may precipitate and grow up along the [111] direction, which has lower surface energy. The appearance of $O$ in the EDS spectrum is a direct evidence of this oxygen assisted VLS growth mechanism.

The second sample is the other important covalent carbide, $\mathrm{B}_{4} \mathrm{C}$, a lightweight refractory semiconductor. Fig. $4 \mathrm{a}$ shows a representative SEM image of the bulk powder, indicating an abundance of straight, smooth, and uniform nanowires with the length over $5 \mu \mathrm{m}$. TEM image (Fig. $4 \mathrm{~b}$ ) reveals a quasi-sphericalshaped catalyst particle at the tip of the $\mathrm{B}_{4} \mathrm{C}$ NW. The EDS spectrum (Fig. 4c) shows that there are $\mathrm{C}, \mathrm{B}, \mathrm{O}, \mathrm{Si}$, and $\mathrm{Ni}$ peaks at the catalyst part, indicating that the $\mathrm{C}-\mathrm{B}-\mathrm{O}-\mathrm{Si}-\mathrm{Ni}$ nanoparticle acts as catalyst for the growth of $\mathrm{B}_{4} \mathrm{C}$ NWs. Fig. $4 \mathrm{~d}$ is the 

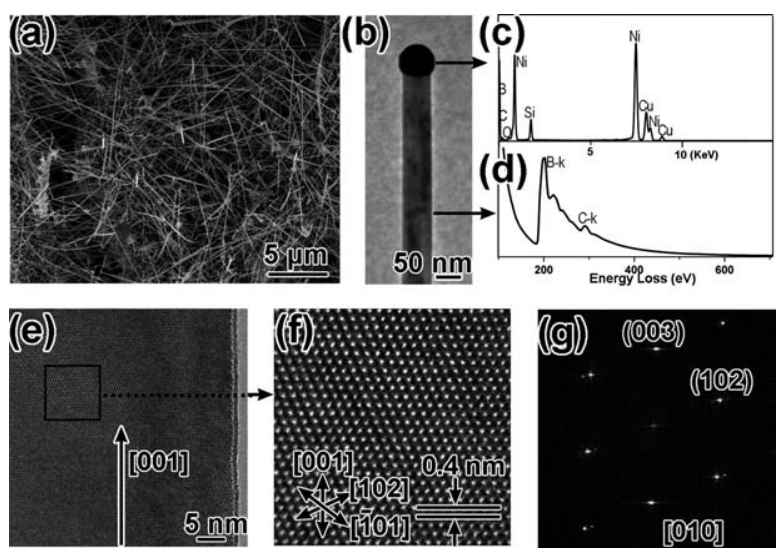

Fig. 4 (a) Typical morphology of the $\mathrm{B}_{4} \mathrm{C}$ NWs from SEM observation. (b) TEM image of a $\mathrm{B}_{4} \mathrm{C} \mathrm{NW}$ with a catalyst on the tip. (c) The corresponding EDS spectrum obtained from the catalyst. (d) The EELS spectrum obtained from the NW. (e) Low magnification HRTEM image of a $\mathrm{B}_{4} \mathrm{C}$ NW. (f) High magnification HRTEM image of the $\mathrm{B}_{4} \mathrm{C} N \mathrm{NW}$ in (e). (g) The corresponding FFT diffraction pattern obtained from (e).

electron energy loss spectrum (EELS) taken from the NW stem. Two distinct absorption features are revealed, one starting at 189 $\mathrm{eV}$ and the other at $285 \mathrm{eV}$, corresponding to the known B-k and $\mathrm{C}-\mathrm{k}$ edges of $\mathrm{B}_{4} \mathrm{C},{ }^{19}$ respectively, which indicates that the nanowire is composed of B and C. [010] zone axis HRTEM image (Fig. 4e) reveals that the NW has a smooth and clear surface. High magnification HRTEM image (Fig. 4f) and the corresponding FFT diffraction pattern (Fig. $4 \mathrm{~g}$ ) prove that the NW is a single crystal with a growth direction along [001]. The spacing between two adjacent lattice fringes is $0.4 \mathrm{~nm}$ (Fig. 4f), agreeing well with the spacing of the $\{003\}$ planes of rhombohedral $\mathrm{B}_{4} \mathrm{C}$.

During our experiments, we found that both $\mathrm{Si}$ and Ni played key roles in the synthesis of $\mathrm{B}_{4} \mathrm{C}$ NW. No $\mathrm{B}_{4} \mathrm{C}$ NWs can be obtained if no Ni precursor was introduced. Only a few $\mathrm{B}_{4} \mathrm{C}$ NWs can be obtained if no $\mathrm{Si}$ was introduced, implying that $\mathrm{Si}$ can enhance the catalytic growth of $\mathrm{B}_{4} \mathrm{C}$ NWs. In our previous work, it was found that the small amount of Si was critical for easy formation of quasi-solid alloy catalyst nanoparticles and the initiation of VLS growth of B nanowires. ${ }^{40}$ The addition of $\mathrm{Si}$ could decrease the eutectic temperature of the catalyst particle containing $\mathrm{B}$ and $\mathrm{Au}$. The eutectic temperatures for $\mathrm{Ni}-\mathrm{B}$ and $\mathrm{Ni}-\mathrm{C}$ are 1018 and $1326{ }^{\circ} \mathrm{C}$, respectively. ${ }^{19,20}$ However, the eutectic temperature of $\mathrm{Ni}-\mathrm{Si}$ is as low as $800^{\circ} \mathrm{C}$. In the present work, it was believed that $\mathrm{Si}$ played a similar role in decreasing the eutectic temperature of the catalyst.

Based on our experimental results, an oxygen assisted VLS growth mechanism similar to that of $\mathrm{SiC} \mathrm{NWs} \mathrm{can} \mathrm{be} \mathrm{suggested} \mathrm{as}$ follows. The hydrocarbon gases generated from the pyrolysis of bamboo serve as the carbon source. The amorphous boron powders contain a tremendous amount of boron atoms that are randomly bonded to one another without long range order. It can be oxidized to form boron oxide vapor such as $\mathrm{B}_{2} \mathrm{O}_{2}$ by the residual oxygen in the furnace and/or the $\mathrm{H}_{2} \mathrm{O}$ vapor generated by the pyrolysis of bamboo and the $\mathrm{Ni}$ precursor $\left(\mathrm{Ni}\left(\mathrm{NO}_{3}\right)_{2} \cdot 6 \mathrm{H}_{2} \mathrm{O}\right)$ :

$$
\begin{gathered}
\mathrm{B}(\mathrm{s})+(x / 2) \mathrm{O}_{2}(\mathrm{v}) \rightarrow \mathrm{BO}_{x}(\mathrm{v}) \\
\mathrm{B}(\mathrm{s})+(x) \mathrm{H}_{2} \mathrm{O}(\mathrm{v}) \rightarrow \mathrm{BO}_{x}(\mathrm{v})+x \mathrm{H}_{2}(\mathrm{v})
\end{gathered}
$$

Meanwhile, silicon vapor $\mathrm{SiO}_{x}$ can also be formed. The $\mathrm{Ni}$ particles can absorb $\mathrm{C}, \mathrm{BO}_{x}$ and $\mathrm{SiO}_{x}$ to form $\mathrm{C}-\mathrm{B}-\mathrm{O}-\mathrm{Si}-\mathrm{Ni}$ nanoparticle:

$$
\begin{gathered}
\mathrm{SiO}_{x}(\mathrm{v})+\mathrm{BO}_{x}+\mathrm{C}(\mathrm{v} \text { or } \mathrm{l})+\mathrm{Ni}(\mathrm{l} \text { or s }) \rightarrow \\
\text { C-B-O-Si-Ni (1 or s) }
\end{gathered}
$$

Continuous dissolution of $\mathrm{B}, \mathrm{C}$ and $\mathrm{Si}$ vapors leads to a supersaturated nanoparticle. $\mathrm{B}_{4} \mathrm{C} \mathrm{NW}$ growth takes place by the precipitation from the supersaturated catalyst particle.

Besides the covalent carbides, interstitial carbides can also be synthesized using bamboo as both the template and the carbon source. Interstitial carbides such as $\mathrm{TiC}, \mathrm{TaC}$, and $\mathrm{NbC}$, are wellknown for their high melting points, high degree of hardness, thermal conductivity, electrical conductivity, and even superconductivity. ${ }^{4,22,25,32,41-43}$ The third sample is TiC, the most common interstitial carbide. A representative SEM image (Fig. 5a) reveals that the TiC product is mainly composed of straight nanowires with typical length larger than $2 \mu \mathrm{m}$. TEM analysis proves that most of the TiC NWs have catalyst particles on the tip of each NW (Fig. 5b). The EDS analysis shows that the attached particle mainly consists of $\mathrm{C}, \mathrm{Ti}$ and $\mathrm{Ni}$ (Fig. 5c). The EDS spectrum from the wire stem (Fig. 5d) reveals that the wire contains $\mathrm{C}$ and $\mathrm{Ti}$ only. It was difficult to detect the $\mathrm{O}$ signals. Fig. 5e is a representative [011] zone axis HRTEM image of the TiC NW. Fig. $5 \mathrm{f}$ is a high magnification HRTEM image taken from the rectangular area marked in Fig. 5e. The spacing between two adjacent lattice fringes is $0.22 \mathrm{~nm}$, corresponding well to the spacing of the $\{100\}$ planes of cubic TiC. Fig. $5 \mathrm{~g}$ shows the corresponding indexed FFT pattern of the TiC NW in Fig. 5e and f. The sharp diffraction spots indicate that the TiC NW is a single crystal with the growth direction along [100].

The fourth sample is $\mathrm{TaC}$, another important interstitial carbide with the highest reported melting point $\left(4200^{\circ} \mathrm{C}\right)$ of any known materials. A representative SEM image (Fig. 6a) shows that the product is composed of straight NWs with the length larger than $15 \mu \mathrm{m}$. The TEM image (Fig. 6b) shows that the $\mathrm{TaC}$ NW terminates at the one containing C, Ta, and Ni (Fig. 6c). The
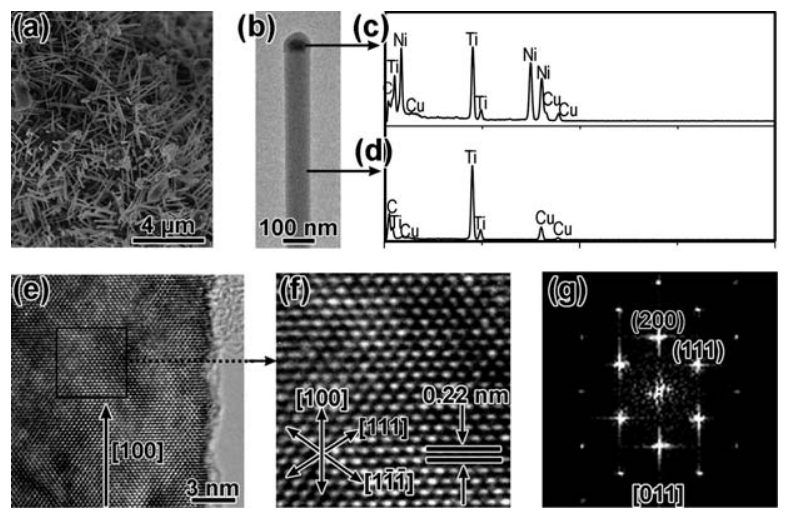

Fig. 5 (a) Typical morphology of the TiC NWs from SEM observation. (b) TEM image of a TiC NW with a catalyst on the tip. (c and d) The corresponding EDS spectra obtained from the catalyst and the NW, respectively. (e) HRTEM image of a TiC NW. (f) High magnification HRTEM image of the TiC NW in (e). (g) The corresponding FFT diffraction pattern obtained from (e). 

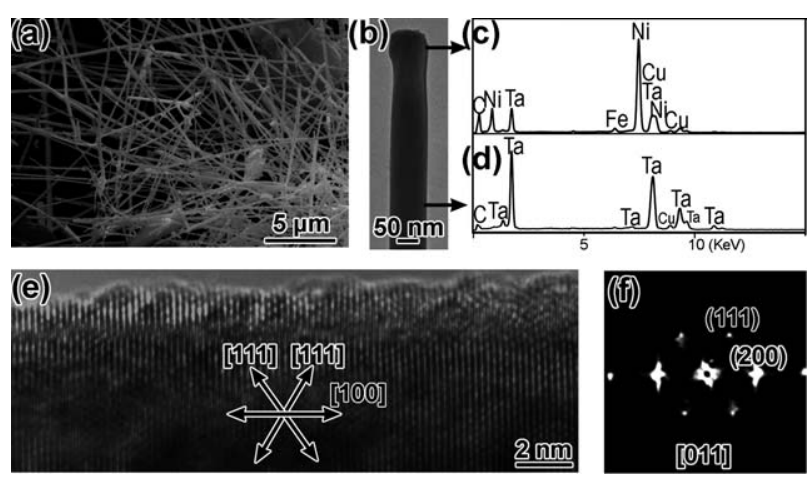

Fig. 6 (a) Typical morphology of the TaC NWs from SEM observation. (b) TEM image of a TaC NW with a catalyst on the tip. (c and d) The corresponding EDS spectra obtained from the catalyst and the NW stem, respectively. (e) [011] zone axis HRTEM image of a TaC NW. (f) The corresponding FFT diffraction pattern obtained from (e).

EDS spectrum (Fig. 6d) from the NW stem shows that the wire contains $\mathrm{C}$ and Ta only. No $\mathrm{O}$ signal can be detected. The typical [011] zone axis HRTEM image (Fig. 6e) and the corresponding FFT diffraction pattern (Fig. 6f) of the NW show that the NW is a single crystal with the growth direction along [100] of cubic $\mathrm{TaC}$.

The fifth sample is $\mathrm{NbC}$, a typical interstitial carbide with high melting point $\left(3610^{\circ} \mathrm{C}\right)$, high hardness, high toughness and Young's modulus, excellent chemical stability, and good wear resistance. $\mathrm{NbC}$ also exhibits high conductivity with a normal resistivity of $4.60 \mathrm{~m} \Omega \mathrm{cm}^{-1}$ and superconductivity at $12 \mathrm{~K} .^{44,45}$ SEM image (Fig. 7a) reveals that the product consists of tremendous amounts of straight NWs with the length over 10 $\mu \mathrm{m}$. Similar to the TiC and TaC NWs, the NbC NWs are single crystalline and grow along [100] direction of cubic $\mathrm{NbC}$, as shown in Fig. 7b and c. Fig. 7d is a low magnification EFTEM image of a $\mathrm{NbC} \mathrm{NW}$ with a catalyst nanoparticle on the tip. Fig. 7e is a zero-loss EFTEM image indicating the morphology of the catalyst in Fig. 7d. Fig. 7f, g, h and $i$ are the corresponding $\mathrm{C}, \mathrm{Fe}, \mathrm{Ni}$, and $\mathrm{Nb}$ maps, respectively. Fig. $7 \mathrm{j}$ is the EDS spectrum
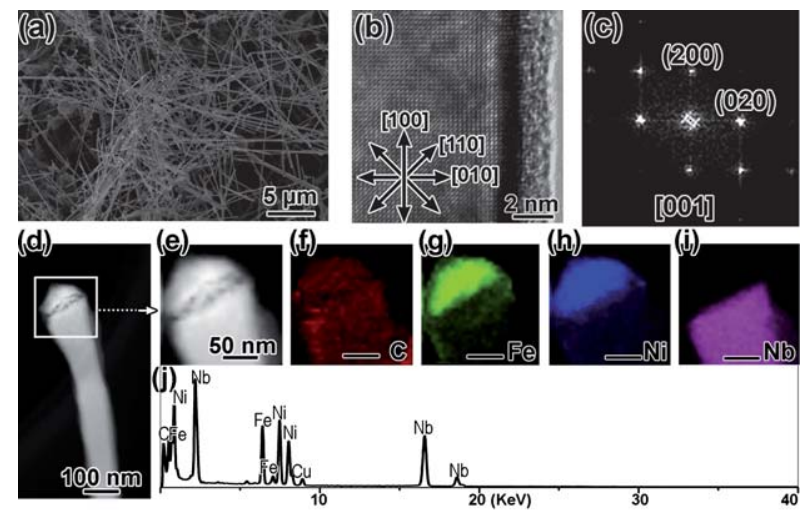

Fig. 7 (a) Typical morphology of the NbC NWs from SEM observation. (b) [001] zone axis HRTEM image of a NbC NW. (f) The corresponding FFT diffraction pattern. (d) Low magnification EFTEM image of a NW with a catalyst nanoparticle on the tip. (e) Zero-loss image indicating the morphology of the catalyst. (f), (g), (h), and (i) Respective C, Fe, Ni, and $\mathrm{Nb}$ maps. (j) The EDS spectrum obtained from (e). obtained from the whole region in Fig. 7e. The $\mathrm{C}$ mapping (Fig. 7f) demonstrates that the $\mathrm{C}$ atoms distribute both in the catalyst and in the stem. The Fe (Fig. 7g) and Ni (Fig. 7h) mappings show that $\mathrm{Fe}$ and $\mathrm{Ni}$ are rich only in the catalyst part, indicating that $\mathrm{Fe}$ and $\mathrm{Ni}$ are primary components of the catalyst nanoparticle. The $\mathrm{Nb}$ mapping (Fig. 7i) demonstrates that the $\mathrm{Nb}$ atoms mainly distribute in the stem, indicating that the NW contains $\mathrm{C}$ and $\mathrm{Nb}$ only.

In addition to the regular pure carbide compounds, some complex solid solution carbide NWs can also be synthesized via this bamboo based carbothermal method. Cubic $\mathrm{Ti}_{x} \mathrm{Nb}_{1-x} \mathrm{C}$ NWs were chosen as the sixth sample to demonstrate the extensive applicability of the bamboo. A representative TEM image (Fig. 8a) shows that the product consists of NWs with a diameter ranging from 80 to $110 \mathrm{~nm}$ and the length larger than $1 \mu \mathrm{m}$. Most of these NWs are straight, as shown in Fig. 8a and b. Some curved $\mathrm{Ti}_{x} \mathrm{Nb}_{1-x} \mathrm{C}$ NWs can also be found (Fig. 8a). The [001] zone axis HRTEM images (Fig. $8 \mathrm{c}$ and d) and the corresponding FFT diffraction pattern (Fig. 8e) reveal that the $\mathrm{Ti}_{x} \mathrm{Nb}_{1-x} \mathrm{C} \mathrm{NW}$ is single crystalline. Different from the NWs of pure carbide compounds such as $\mathrm{TiC}, \mathrm{TaC}$, and $\mathrm{NbC}$ with [100] growth direction, $\mathrm{Ti}_{x} \mathrm{Nb}_{1-x} \mathrm{C}$ NWs have a growth direction approximately parallel to [210]. Fig. 8f is a zero-loss EFTEM image showing the morphology of the NW with a catalyst nanoparticle. Fig. 8g, h, i and $\mathrm{j}$ are corresponding $\mathrm{C}, \mathrm{Ti}, \mathrm{Fe}$, and $\mathrm{Nb}$ maps, respectively. Fig. 8k is the EDS spectrum obtained from the whole area of Fig. 8f. The C (Fig. 8g), Ti (Fig. 8h) and $\mathrm{Nb}$ (Fig. 8j) maps demonstrate that the $\mathrm{C}, \mathrm{Ti}$, and $\mathrm{Nb}$ atoms distribute both in the catalyst and in the stem, indicating that the $\mathrm{Ti}_{x} \mathrm{Nb}_{1-x} \mathrm{C}$ solid solution NWs can be obtained using bamboo as both the carbon source and the template. The background signals of $\mathrm{C}$ mapping come from the $\mathrm{C}$ film coating on TEM grids. The Fe mapping (Fig. 8i) shows that Fe is rich only in the catalyst part.

The last example is cubic $\mathrm{Ta}_{x} \mathrm{Nb}_{1-x} \mathrm{C}$, which is a new superconducting material. ${ }^{41}$ A typical TEM image (Fig. 9a) shows that the product consists of abundant NWs with a diameter ranging from 60 to $140 \mathrm{~nm}$ and the length larger than $1 \mu \mathrm{m}$. Different from NWs of other pure carbides such as $\mathrm{B}_{4} \mathrm{C}, \mathrm{TiC}, \mathrm{NbC}$, and $\mathrm{TaC}$, which are straight in morphology and smooth in surface, some $\mathrm{Ta}_{x} \mathrm{Nb}_{1-x} \mathrm{C}$ NWs exhibit intriguing morphological

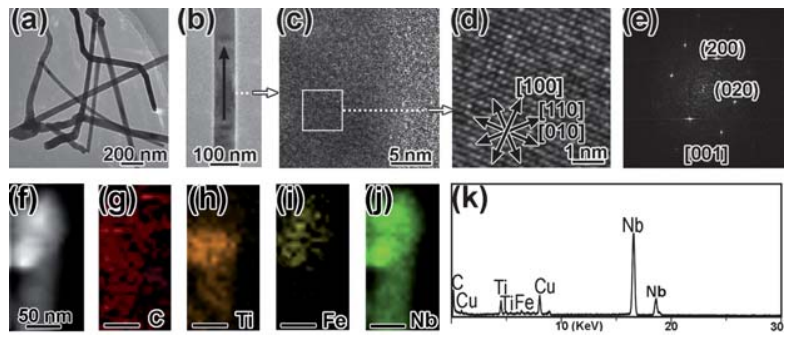

Fig. 8 (a) Typical morphology of the $\mathrm{Ti}_{x} \mathrm{Nb}_{1-x} \mathrm{C}$ NWs from TEM observation. (b) TEM image of a single NW. (c) The corresponding low magnification HRTEM image of (b). (d) High magnification HRTEM image from the rectangular area in (c). (e) The corresponding FFT diffraction pattern obtained from (d). (f) Zero-loss image, indicating the morphology of the NW with a catalyst nanoparticle. (g), (h), (i), and (j) Respective $\mathrm{C}, \mathrm{Ti}, \mathrm{Fe}$, and $\mathrm{Nb}$ maps. (K) The EDS spectrum obtained from (f). 

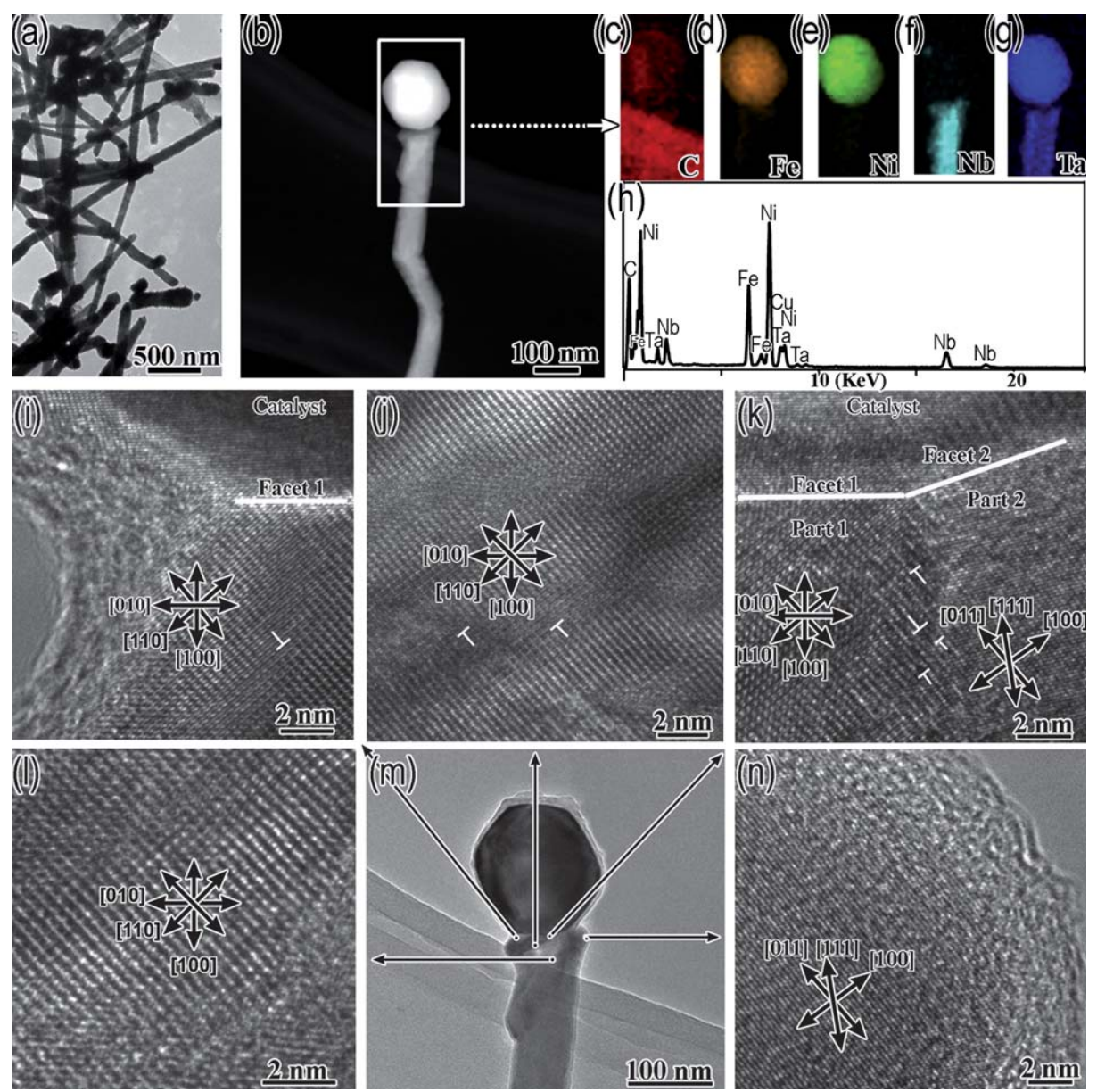

Fig. 9 (a) Typical morphology of the $\mathrm{Ta}_{x} \mathrm{Nb}_{1-x} \mathrm{C}$ NWs from TEM observation. (b) EFTEM image of a single NW with a catalyst particle on the tip. (c), (d), (e), (f), and (g) Respective C, Fe, Ni, Nb, and Ta maps obtained from the rectangular area in (b). (h) The EDS spectrum obtained from area (c). (m) The bright field TEM image of the NW attached to a catalyst particle. (i), (j), (k), (l), and (n) Corresponding HRTEM images from different areas marked by the arrows in (m).

characteristics such as curved and branched shapes (Fig. 9a). EFTEM image (Fig. 9b) reveals that there is a catalyst nanocrystal with facets on the tip of the NW, indicating the VLS growth mechanism. Fig. 9c, d, e, f, and $\mathrm{g}$ are corresponding $\mathrm{C}$, $\mathrm{Fe}, \mathrm{Ni}, \mathrm{Nb}$, and Ta maps, respectively. Fig. $9 \mathrm{~h}$ is the EDS spectrum obtained from the whole area in Fig. $9 \mathrm{c}-\mathrm{g}$. The element maps (Fig. 9c-g) prove that the catalyst contains $\mathrm{C}, \mathrm{Ni}, \mathrm{Fe}, \mathrm{Ta}$ and a small quantity of $\mathrm{Nb}$. The strong background signals of $\mathrm{C}$ come from the TEM grid. The Nb (Fig. 9f) and Ta (Fig. 9g) maps reveal that there is a continuous uniform distribution of $\mathrm{Nb}$ and $\mathrm{Ta}$ in the NW stem, indicating that $\mathrm{Ta}_{x} \mathrm{Nb}_{1-x} \mathrm{C}$ solid solution NWs have been synthesized. Fig. $9 \mathrm{~m}$ is the bright field TEM image of the NW with a catalyst nanocrystal.

Fig. 9i- 1 and $n$ are the corresponding HRTEM images from different areas as indicated by the arrows in Fig. 9m. Fig. 9i shows a clear interface between the catalyst (Facet 1) and the NW. It can be found that the growth direction [100] is approximately perpendicular to Facet 1. Abundant edge dislocations and obvious lattice distortion can be observed in Fig. 9i, j and 1. Compared with the pure defect-free $\mathrm{NbC}$ NWs, the dislocations and obvious lattice distortion may result from the internal strain caused by the slight difference in lattice spacing of $\mathrm{Ta}-\mathrm{C}$ and $\mathrm{Nb}-$
C. Fig. 9k is the HRTEM image of the other end of the interface between the catalyst and the NW. The second facet (Facet 2) can be found in Fig. 9k. Different from the NW (Part 1) connected with Facet 1, the NW (Part 2) connected with Facet 2 has different crystallographic orientation. Fig. $9 \mathrm{n}$ is the elongation of Part 2. The [110] direction of Part 1 is parallel to the [100] direction of Part 2. Abundant misfit dislocations can be found at the interface between Part 1 and Part 2 (Fig. 9k). VLS is a wellestablished process in catalyst-guided growth of NWs. During the VLS growth of one dimensional nanostructures, the growth behavior strongly depends on the crystallographic orientation of the quasi-solid catalyst nanoparticle. ${ }^{46}$ The difference in the growth direction of Part 1 and Part 2 may result from the different precipitation behavior of Facet 1 and Facet 2.

In our experiments, it was found that the $\mathrm{Ni}$ and/or Fe catalyst and the halide precursors played key roles in the growth of these interstitial carbide $\mathrm{NWs}$ including $\mathrm{TiC}, \mathrm{TaC}, \mathrm{NbC}, \mathrm{Ti}_{x} \mathrm{Nb}_{1-x} \mathrm{C}$, and $\mathrm{Ta}_{x} \mathrm{Nb}_{1-x} \mathrm{C}$. Our control experiments, where no catalyst (Fe and/or $\mathrm{Ni}$ ) or halide precursor was introduced to the system, showed essentially that no NW was obtained in the product. Gaseous halide species such as $\mathrm{TaOF}_{3}(\mathrm{~g}), \mathrm{TaF}_{5}(\mathrm{~g}), \mathrm{TaF}_{4}(\mathrm{~g})$, $\mathrm{NbOF}_{3}(\mathrm{~g}), \mathrm{NbF} 4(\mathrm{~g}), \mathrm{NbF}_{5}(\mathrm{~g}), \mathrm{TiOF}_{2}(\mathrm{~g}), \mathrm{TiO}_{2} \mathrm{~F}(\mathrm{~g}), \mathrm{TiF}_{4}(\mathrm{~g})$ 
and $\mathrm{TiF}_{3}(\mathrm{~g})$ were formed at the reaction temperature and must be responsible for the transport of the corresponding transition metals (TM) including $\mathrm{Ti}$, $\mathrm{Ta}$, and $\mathrm{Nb}$. The following generic reactions are expected to occur during the growth of these interstitial carbide NWs:

$\mathrm{TMO}_{x} \mathrm{Fy}+2 \mathrm{C}(\mathrm{g}, \mathrm{l})+\mathrm{Ni}, \mathrm{Fe}(\mathrm{l}) \rightarrow \mathrm{Ni}, \mathrm{Fe}(\mathrm{TM}, \mathrm{C})(\mathrm{l})+y \mathrm{~F}(\mathrm{~g})+$ $\mathrm{CO}_{x}(\mathrm{~g})$

$$
\mathrm{Ni}, \mathrm{Fe}(\mathrm{TM}, \mathrm{C})(\mathrm{l}) \rightarrow \mathrm{TMC}(\mathrm{s})+\mathrm{Ni}, \mathrm{Fe}(\mathrm{l})
$$

All these reactions were not consecutive but probably occurred simultaneously during the VLS growth of interstitial carbide NWs. Ni and Fe have been proved to be high efficient catalysts for CNTs, and accordingly $\mathrm{Ni}$ (l) and $\mathrm{Fe}$ (l) are known to solvate $\mathrm{C}$ and TM. When the catalyst liquid nanoparticles Ni, Fe (TM, C) supersaturate with TM and C, the NWs may precipitate and grow up. Although some AC can be formed due to the incomplete pyrolysis of cellulose, they can be easily removed by airoxidation to get high purity carbide NWs.

\section{Conclusions}

We have demonstrated a generic bamboo-based carbothermal method for preparing NWs of both covalent carbides ( $\mathrm{SiC}$ and $\mathrm{B}_{4} \mathrm{C}$ ) and interstitial carbides $\left(\mathrm{TiC}, \mathrm{TaC}, \mathrm{NbC}, \mathrm{Ti}_{x} \mathrm{Nb}_{1-x} \mathrm{C}\right.$, and $\mathrm{Ta}_{x} \mathrm{Nb}_{1-x} \mathrm{C}$ ). The use of natural nanoporous bamboo as both the renewable carbon source and the template for the formation of catalyst particles greatly simplifies the synthesis process. Based on the structural, morphological and elemental analysis, a volatile oxides and/or halides assisted VLS growth mechanism was proposed. This bamboo-based carbothermal method has the following unique advantages. First, bamboo with natural porous microstructures can be used as both the template and the green renewable carbon source, which can substitute the traditional fossil-fuel based carbon sources. Second, this simple and convenient carbothermal method, based on the outstanding absorbing ability of bamboo, makes it easy to control the component of NWs. Third, the raw materials are quite inexpensive and the entire synthesis process is cost-effective. The yield is high and it is readily expandable for large-scale production to meet the need of industry high throughput manufacturing. Finally, the synthesis process is nontoxic without producing hazardous waste. This bamboo based carbothermal method can be generalized to other carbide systems, providing a general, one-pot, simple, convenient, mass production, and innovative strategy for the synthesis of carbide nanostructures. These new carbide NWs possess great potential for applications in nano-composites, nano-sensors, nano-electronic devices, and superconducting circuits.

\section{Acknowledgements}

This work was supported by the NSFC (51002138), the Zhejiang Provincial NSF of China (Y4090420), the Qianjiang Talent Project (2010R10029), the 'Qianjiang Scholars' program' and the project-sponsored by SRF for ROCS (2010609), State Education Ministry of China, and the U.S. NSF (CMMI-0968843, CMMI0824728, and CMMI-0653651).

\section{References}

1 H. H. Hwu and J. G. G. Chen, Chem. Rev., 2005, 105, 185.

2 D. E. Grove, U. Gupta and A. W. Castleman, ACS Nano, 2010, 4, 49.

3 T. H. Lee, S. Bhunia and M. Mehregany, Science, 2010, 329, 1316.

4 G. F. Zou, H. Y. Wang, N. Mara, H. M. Luo, N. Li, Z. F. Di, E. Bauer, Y. Q. Wang, T. McCleskey, A. Burrell, X. H. Zhang, M. Nastasi and Q. Jia, J. Am. Chem. Soc., 2010, 132, 2516.

5 T. Ishikawa, Y. Kohtoku, K. Kumagawa, T. Yamamura and T. Nagasawa, Nature, 1998, 391, 773.

6 D. Nakamura, I. Gunjishima, S. Yamaguchi, T. Ito, A. Okamoto, H. Kondo, S. Onda and K. Takatori, Nature, 2004, 430, 1009.

7 C. R. Eddy and D. K. Gaskill, Science, 2009, 324, 1398.

8 H. W. Hugosson, U. Jansson, B. Johansson and O. Eriksson, Science, 2001, 293, 2434

9 M. W. Chen, J. W. McCauley and K. J. Hemker, Science, 2003, 299, 1563.

10 Y. F. Zhang, X. D. Han, K. Zheng, Z. Zhang, X. N. Zhang, J. Y. Fu, Y. Ji, Y. J. Hao, X. Y. Guo and Z. L. Wang, Adv. Funct. Mater., 2007, 17, 3435.

11 Y. B. Li, Y. Bando and D. Golberg, Adv. Mater., 2004, 16, 93.

12 Y. B. Li, P. S. Dorozhkin, Y. Bando and D. Golberg, Adv. Mater., $2005, \mathbf{1 7}, 545$.

13 Z. W. Pan, H. L. Lai, F. C. K. Au, X. F. Duan, W. Y. Zhou, W. S. Shi, N. Wang, C. S. Lee, N. B. Wong, S. T. Lee and S. S. Xie, Adv. Mater., 2000, 12, 1186.

14 S. V. Pol, V. G. Pol and A. Gedanken, Adv. Mater., 2006, 18, 2023.

15 C. N. R. Rao and A. Govindaraj, Adv. Mater., 2009, 21, 4208.

16 C. C. Tang, Y. Bando, T. Sato and K. Kurashima, Adv. Mater., 2002, 14, 1046.

17 X. Y. Tao, L. X. Dong, X. N. Wang, W. K. Zhang, B. J. Nelson and X. D. Li, Adv. Mater., 2010, 22, 2055.

18 D. T. Welna, J. D. Bender, X. L. Wei, L. G. Sneddon and H. R. Allcock, Adv. Mater., 2005, 17, 859.

19 W. Q. Han, Appl. Phys. Lett., 2006, 88, 133118.

20 R. Ma and Y. Bando, Chem. Mater., 2002, 14, 4403.

21 E. W. Wong, B. W. Maynor, L. D. Burns and C. M. Lieber, Chem. Mater., 1996, 8, 2041.

22 C. H. Liang, G. W. Meng, W. Chen, Y. W. Wang and L. D. Zhang, J. Cryst. Growth, 2000, 220, 296.

23 S. R. Qi, X. T. Huang, Z. W. Gan, X. X. Ding and Y. Cheng, J. Cryst. Growth, 2000, 219, 485.

24 J. Q. Wei, B. Jiang, Y. H. Li, C. L. Xu, D. H. Wu and B. Q. Wei, J. Mater. Chem., 2002, 12, 3121 .

25 T. Taguchi, H. Yamamoto and S. I. Shamoto, J. Phys. Chem. C, 2007, 111, 18888.

26 J. Frechette and C. Carraro, J. Am. Chem. Soc., 2006, 128, 14774.

27 X. H. Sun, C. P. Li, W. K. Wong, N. B. Wong, C. S. Lee, S. T. Lee and B. K. Teo, J. Am. Chem. Soc., 2002, 124, 14464.

28 X. L. Feng, M. H. Matheny, C. A. Zorman, M. Mehregany and M. L. Roukes, Nano Lett., 2010, 10, 2891.

29 X. D. Han, Y. F. Zhang, K. Zheng, X. N. Zhang, Z. Zhang, Y. J. Hao, X. Y. Guo, J. Yuan and Z. L. Wang, Nano Lett., 2007, 7, 452.

30 G. W. Ho, A. S. W. Wong, A. T. S. Wee and M. E. Welland, Nano Lett., 2004, 4, 2023.

31 G. Mpourmpakis, G. E. Froudakis, G. P. Lithoxoos and J. Samios, Nano Lett., 2006, 6, 1581.

32 K. F. Huo, Y. M. Hu, Y. W. Ma, Y. N. Lu, Z. Hu and Y. Chen, Nanotechnology, 2007, 18, 145615.

33 H. J. Dai, E. W. Wong, Y. Z. Lu, S. S. Fan and C. M. Lieber, Nature, 1995, 375, 769.

34 E. W. Wong, P. E. Sheehan and C. M. Lieber, Science, 1997, 277, 1971.

35 D. Q. Zhang, A. Alkhateeb, H. M. Han, H. Mahmood, D. N. McIlroy and M. G. Norton, Nano Lett., 2003, 3, 983.

36 A. Velamakanni, K. J. Ganesh, Y. W. Zhu, P. J. Ferreira and R. S. Ruoff, Adv. Funct. Mater., 2009, 19, 3926.

37 E. L. K. Mui, W. H. Cheung, V. K. C. Lee and G. McKay, Ind. Eng. Chem. Res., 2008, 47, 5710.

38 L. Li, Chemisty and Applications of Bamboo, Zhejiang University Press, Hangzhou, China, 2006, p. 85.

39 D. K. Shen and S. Gu, Bioresour. Technol., 2009, 100, 6496.

40 X. Y. Tao, J. Liu, G. Koley and X. D. Li, Adv. Mater., 2008, 20, 4091. 
41 S. R. Vallance, D. M. Round, C. Ritter, E. J. Cussen, S. Kingman and D. H. Gregory, Adv. Mater., 2009, 21, 4502.

42 D. W. Flaherty, R. A. May, S. P. Berglund, K. J. Stevenson and C. B. Mullins, Chem. Mater., 2010, 22, 319.

43 N. Ahlen, M. Johnsson, A. K. Larsson and B. Sundman, J. Eur. Ceram. Soc., 2000, 20, 2607.
44 J. H. Ma, M. N. Wu, Y. H. Du, S. Q. Chen, W. Jin, L. Fu, Q. Y. Yang and A. F. Wen, J. Alloys Compd., 2009, 475, 415.

45 L. Shi, Y. L. Gu, L. Y. Chen, Z. H. Yang, J. H. Ma and Y. T. Qian, J. Phys.: Condens. Matter, 2004, 16, 8459.

46 X. Y. Tao, X. B. Zhang, J. P. Cheng, Y. W. Wang, F. Liu and Z. Q. Luo, Chem. Phys. Lett., 2005, 409, 89. 